\title{
O PROFISSIONAL DOCENTE DO DIREITO: REFLETINDO SOBRE SUA PRÁTICA PEDAGÓGICA
}

\author{
P. Z. OLIVEIRA*, R. A. GEBRAN \\ Mestrado em Educação - Universidade do Oeste Paulista (UNOESTE) \\ ragebran@hotmail.com
}

Submetido 03/03/2016 - Aceito 03/09/2018

DOI: $10.15628 /$ holos.2018.4206

\section{RESUMO}

O trabalho apresenta reflexão sobre a ação docente do profissional do Direito em sua prática. As escolas de Direito fomentam a participação dos professores profissionais do Direito (advogados, juízes, etc), por acreditar quão importantes são para seus alunos as experiências forenses dos juristas professores. Questiona-se se apenas os saberes da formação acadêmica e os da experiência são capazes de transformar bons profissionais do Direito em bons professores. A pesquisa teve como objetivo central investigar como se configura a ação docente do profissional da área do Direito na atuação no ensino superior. Procurou-se identificar as concepções que os professores juristas têm sobre a docência. Verificaramse os limites e as possibilidades que apresentam no exercício da docência. $O$ estudo centrou-se na abordagem qualitativa, configurando-se como um estudo de caso. Os procedimentos metodológicos envolveram coleta de dados, por meio de entrevistas com roteiro semiestruturado e análise documental do Projeto Político Pedagógico. A análise dos dados permitiu afirmar que este grupo de professores acredita na necessidade da formação pedagógica para a docência, percebe a importância da formação continuada, da atualização e da socialização em sala de aula.

PALAVRAS-CHAVE: Curso de Direito; docência; formação docente; prática pedagógica.

\section{THE LAW PROFESSIONAL AND HIS PEDAGOGICAL TRAINING: CHALLENGES AND COMMITMENTS}

\begin{abstract}
The actual research was intended to contribute in the reflection on the work of the Law Professional and his use in the faculty action. It is already known that Law schools foment the participation of professors who are Law Professionals (lawyers, judges, prosecutors among others) because they certainly know how important it is for students, the experience and forensic practices emanated from jurist professors. However, it is questioned: is the knowledge originated from academic education and the knowledge gained from experience alone able to transform good Law professionals in good professors? How does such knowledge articulate with pedagogical practice? Is the pedagogical training important for the professor, specially the Law professor? What are the problems and motivations for the professors' practice? Facing all these questions, the
\end{abstract}

main target of this research was to investigate the way the professional action of professors configure itself in the Law area when acting in the superior education. It was necessary to identify the conceptions that Law professors have concerning teaching, through the analysis of their pedagogical practices, verifying the limits and possibilities for their teaching performance. The study was centered on the qualitative approach, with the study of a case. The methodological procedures involved gathering of data, through interviews with a semi structured script and documental analysis. The analysis of data allowed us to assert that this group of professors believe in the importance of pedagogical training for the actual teaching, they realize the importance of continuous training, updating and socialization in the classroom.

KEYWORDS: Law school, teaching, teacher training, teaching practice 


\section{INTRODUÇÃO}

É indiscutível que, neste início de século XXI, o mundo se defronta com um novo cenário de dimensões políticas, filosóficas, econômicas, culturais e tecnológicas, que exige para a formação de profissionais e, especialmente, para a formação do professor mudança urgente de paradigma para enfrentar os desafios que a sociedade impõe.

As universidades, como integrantes desse cenário são provocadas a enfrentamentos em virtude das novas funções que lhes são demandadas. Para garantir a qualidade do ensino e o equacionamento dos desafios impostos nesse contexto se requer não só desempenhos satisfatórios, mas o constante aprimoramento da prática docente. As propostas pedagógicas institucionais, os projetos pedagógicos dos cursos, a gestão nas suas diferentes dimensões, as relações interpessoais e com a comunidade são elos de um sistema que deve interagir para seu bom funcionamento.

Neste estudo detivemo-nos em discutir alguns aspectos da formação e atuação de um profissional docente específico: o professor de Direito. A questão norteadora foi: Os professores de Direito encontram-se capacitados para desempenhar suas funções como profissionais docentes?

Para tanto, estabelecemos como objetivo central do trabalho investigar como se configura a ação docente do profissional da área do Direito para o exercício da docência, ou seja, para a sua profissionalização docente no ensino superior.

Participaram da pesquisa dez professores de Direito de uma instituição de ensino privada de Presidente Prudente. Procuramos, por meio de entrevistas semiestruturadas, identificar quais são as concepções que os professores de Direito têm sobre a docência e analisar as ações e as práticas pedagógicas que dizem utilizadas, buscando verificar suas motivações para o exercício da docência e levantar as possibilidades, limites e dificuldades em sua ação.

Os dados obtidos por meio desta pesquisa foram trabalhados por meio da análise de conteúdo apresentada por Bardin (1997), que consiste na interpretação do significado das respostas apresentadas pelo pesquisado. As respostas obtidas dos pesquisados foram organizadas em categorias e relacionadas com os objetivos propostos inicialmente na pesquisa. Apresentamos, então, os resultados e achados, entrelaçando aquilo que ouvimos dos sujeitos pesquisados e os aspectos da discussão teórica apresentada.

Pretendemos, com este trabalho, promover reflexões para repensar a prática docente dos profissionais do curso de Direito como forma de contribuir para o aprimoramento do ensino jurídico.

\section{REFERENCIAL TEÓRICO}

\subsection{O ENSINO JURÍDICO E A AÇÃO DOCENTE DO PROFISSIONAL DO DIREITO}

O ensino jurídico, no Brasil, inicia-se com a instalação dos Cursos Jurídicos, criados por Lei em 11 de agosto de 1827, e, efetivamente instalados em 1828, no Convento de São Francisco, em São Paulo (SP), e no Mosteiro de São Bento, em Olinda (PE), fortemente influenciados pelas universidades europeias. 
A formação dos novos acadêmicos era destinada, sobretudo, à composição de uma elite intelectual para a condução da nação, tendo em vista o momento político que reinava na época e que exigia a formação de bacharéis voltados aos postos de comando na estrutura política e administrativa do então novo Estado, recém-proclamado independente da coroa portuguesa (1822).

Este modelo de ensino, evidentemente foi alterado tendo em vista as mudanças políticas, econômicas e sociais que influenciaram a formação dos novos acadêmicos. Com a República passa a centrar-se em uma orientação positivista e conservadora, calcada nos preceitos do filósofo francês Auguste Comte, idealizador do pensamento positivista estatal no século XIX, cuja base epistemológica possui como linha mestra a crença de que a ciência, como instrumento de orientação, pode oferecer respostas para todos os problemas da humanidade. Assim, o positivismo ganhou força como escola do pensamento, centrado na concepção de que as relações sociais são complexas e necessitam de investigações sistematizadas e verificáveis, eliminando ao máximo as suposições ou o risco de interpretações subjetivas e abstratas.

De acordo com essa compreensão positiva da ciência, passou-se, então, a privilegiar os conceitos práticos, técnicos e aplicados dos cursos. É fato que o caráter cientificista valorizado pelos positivistas ajudou a construir uma visão compartilhada de que o Direito é um "sistema de normas jurídicas", sendo Kelsen (2003) responsável pela elaboração da Teoria Pura do Direito, que definiu a estrutura hierárquica das normas. Nos dizeres de Kelsen (2003, p. 79): "apreender algo juridicamente, não pode significar senão apreender algo como Direito, o que quer dizer: como norma jurídica ou conteúdo de uma norma jurídica".

Quando se pensa especificamente no ensino de Direito, temos em Freitas $(2005$, p. 3) o seguinte entendimento

[...] não é apenas um ramo do conhecimento científico, mas também é caracterizado tanto pela abstração normativa como pela práxis judiciária que obrigatoriamente impõem vigência às coisas e pessoas que, dizendo de outra forma, geram conseqüências. Por isto, a presente discussão [o ensino jurídico na graduação, no Brasil] deve ser analisada e estudada com bastante propriedade, inclusive, pois há uma premência em se definir a cultura científico-jurídica dentro do atual conceito de democracia, cidadania e liberdade.

Entende o autor que tal cultura tem-se pautado na ambiguidade a respeito do próprio conceito de Direito, que tem sua base nas normas positivistas, com todas as consequências que isso pode trazer sobre vários aspectos - desde as práticas pedagógicas até o próprio exercício da profissão. Assim, ensino do Direito sempre foi dogmático, desprovido de qualquer valoração. 0 currículo extremamente conservador se materializava nas aulas expositivas e o ensino baseado na análise de códigos comentados.

Entende Wolkmer (2001, p. 72) que:

[...] o Direito está em crise e que a crise do Direito não é uma crise setorial isolada, mas está diretamente relacionada com a crise dos fundamentos e dos paradigmas que norteiam a modernidade, em que a dogmática jurídica estatal não é a causa, mas o efeito da crise cultural valorativa que atravessa o capitalismo no mundo. 
Crivando o olhar sobre o curso do Direito, é impossível não perceber a insatisfação ou o esvaziamento da qualidade que assola o ensino jurídico brasileiro. Pode-se afirmar que o ensino jurídico enfrenta um momento de redefinições e mudanças, objetivando melhorias tanto para os acadêmicos como para a sociedade em geral, que necessita do auxílio dos profissionais do Direito para solucionar as mazelas da vida em sociedade.

Em 1994, a edição da Portaria no 1.886/94 (Brasil, 1994a) objetivou provocar uma readequação dos currículos dos cursos jurídicos à nova realidade social brasileira, já integrada à globalização e à informática. Novas exigências foram inseridas no curso de ensino jurídico, como o avanço metodológico por meio dos Núcleos de Prática Jurídica e da obrigatoriedade da realização de Monografia de Conclusão de curso, de estágios obrigatórios além da exigência referente à realização de atividades complementares paralelas ao curso.

Todavia, em contraponto aos avanços mencionados, verifica-se uma grave redução no nível de formação dos bacharéis, que se manifesta nos baixíssimos índices de aprovação no Exame de Ordem do Conselho Federal da Ordem dos Advogados do Brasil (OAB), bem como nos variados concursos públicos oferecidos ao profissional do Direito. A esse fato, soma-se a expansão indiscriminada dos cursos jurídicos existentes no país.

Martins (2005, p. 5) afirma que os principais entraves nos cursos jurídicos passam pelas resistências colocadas pelos especialistas em Direito; inércia das instituições de ensino, valorizando a herança positivista da especialização e; o apego ao formalismo presente na opção pedagógica da Instituição de Ensino Superior.

Por outro lado, as instituições de ensino superior fomentam a participação de professores juristas em seu quadro de professores e fazem isso porque, certamente, vislumbram o quão importante é para seus alunos o oferecimento de experiências e práticas forenses, emanadas dos juristas professores. Por outro lado, isso tem revelado que apenas a formação acadêmica e a experiência diária do assunto não são capazes de transformar bons profissionais do Direito em bons professores.

Em outras palavras, acreditamos que ser juiz de Direito, promotor, delegado de polícia, desembargador ou advogado, não é pré-requisito para a docência, pois tão importante quanto o conhecimento teórico ou o conteúdo programático é a efetiva ação docente, por meio das boas práticas pedagógicas, que devem propiciar a apropriação e construção de saberes pelos estudantes.

Assim, além do necessário conhecimento especializado no seu segmento de atuação, tornou-se necessário que o aluno tenha conhecimento, também, em economia, sociologia, filosofia, política, etc., para que possa atuar no mercado de trabalho de um mundo globalizado. A inter-relação entre as disciplinas é indispensável para que o aluno consiga interpretar a legislação, doutrina e jurisprudência, bem como aplicar seus ensinamentos no cotidiano forense.

A conjunção desses fatores passou a exigir um maior comprometimento do professor, tanto com relação à sua prática docente como em relação à sua formação e qualificação, visando à superação da crise instalada. Na visão de Gomes (2003), o ensino jurídico em nosso país encontrase submetido a, pelo menos, três crises: (a) político-institucional; (b) científico-ideológica; e (c) metodológica.

A crise político-institucional diz respeito à redefinição do próprio Estado nas sociedades, que passam por um momento de profunda reforma de suas instituições e papéis, com reflexo 
imediato na concepção do Direito e do ensino superior. Do ponto de vista educacional, a crise político-institucional que decorre da configuração moderna deste Estado, chamado de neoliberal, gerou massificação e mercantilização do ensino, acrescentando-se a isso os baixos investimentos públicos para as instituições superiores, pouca infraestrutura e quase nenhum investimento na formação de professores. Na busca de novas proposições os educadores se mobilizaram para criar e desenvolver um viés mais crítico, reflexivo e livre, no espaço educacional e mais próximo dos conceitos democráticos.

Com relação à crise científico-ideológica, nota-se que estão associados a ela os questionamentos científicos e éticos, centrados na ciência moderna e suas limitações. A concepção cartesiana, modelo dominante de como operar o Direito, vem sendo criticada, tendo em vista a necessidade de entender o fenômeno jurídico como um todo e as disciplinas de forma interligada. O Direito, aos poucos, retoma sua vocação, retirando-se do isolamento científico no qual se encontrava e fortalecendo o seu enfoque interdisciplinar, na tentativa de alcançar a sua origem social, os seus fins.

A terceira crise - a metodológica - expõe a falência do método atual para a formação do pensamento crítico do aluno de Direito, para o qual contribui, sem dúvida, a falta de objetivos claros sobre o quê se forma durante o curso de Direito e para quê se forma. Sabe-se que novos modelos e propostas de ensino se colocam como experiências singulares, em todo o país, visando à formação de bacharéis críticos, ativos, dentro e fora da sala de aula, capazes de assumir com competência e ética sua função social.

Nesse sentido, Streck ( ） afirma: "é preciso compreender que a crise do ensino jurídico é, antes de tudo, uma crise do direito, que na realidade é uma crise de paradigmas, assentada em uma dupla face: uma crise de modelo e uma crise de caráter epistemológico". p. 34-35

\section{O autor complementa:}

[...] de um lado, os operadores do direito continuam reféns de uma crise emanada da tradição liberalindividualista-normativista (e iluminista, em alguns aspectos); e, de outro, a crise dos paradigmas epistemológico da filosofia da consciência metafísica moderna - e aristotélico-tomista, da metafísica clássica). O resultado dessa(s) crise(s) é um direito alienado da sociedade, questão que assume foros de dramaticidade se compararmos o texto da Constituição com as promessas da modernidade incumpridas.

Para que possamos pensar em novas metodologias de ensino, é importante que definir o papel do ensino jurídico no Brasil, qual o seu sentido e objetivo. É fato que o Direito guarda uma relação intrínseca com a política. Nessa perspectiva, Bobbio (1988, p. 232) explica:

O problema da relação entre política e direito é um problema muito complexo de interdependência recíproca, [já que] a política tem a ver com o direito sob dois pontos de vista: enquanto a ação política se exerce através do Direito, e enquanto o Direito delimita e disciplina a ação política.

Trata-se de desenvolver uma proposição de estudo do Direito que se configure como parte essencial do contexto sociopolítico no qual está inserido. Isso implicaria "na adoção de métodos interdisciplinares de abordagem das temáticas a serem desenvolvidas, em substituição à perspectiva unidisciplinar, fragmentada e dogmática de transmissão/recepção de conhecimentos pré-fabricados." (Santos, 2002, p.11) 
Para Fazenda (1995), a interdisciplinaridade ocorre por meio de parceira e conscientização e depende mais do encontro entre as pessoas envolvidas (sujeitos) do que entre as disciplinas. A prática interdisciplinar é estabelecida no momento em que existem ações que propiciam diálogos entre as disciplinas e entre os sujeitos das ações, ou seja, ela se desenvolve num trabalho de parceria e reflexão. Quando o ensino é desenvolvido por meios de ações interdisciplinares existe a superação de uma visão fragmentada e linear da produção de conhecimento.

Portanto, a interdisciplinaridade corresponde a uma nova consciência da realidade e a um novo modo de refletir e pensar o ensino, baseados no ato de troca do conhecimento, de reciprocidade entre áreas diferentes, objetivando a construção de novos conhecimentos por meio da busca de resolução para os problemas, das novas reflexões e questionamentos para a elucidação de uma nova realidade.

Apesar das novas proposições o engessamento, a rigidez e o conservadorismo apresentados pelos cursos jurídicos revelam certa resistência e constituem-se nos maiores entraves para a mudança de postura e quebra de paradigmas na formação dos bacharéis em Direito. Por isso, torna-se imprescindível que a discussão acerca do ensino jurídico perpasse as exigências e possibilidades relativas à formação do docente, já que sobre ele paira a responsabilidade social de contribuir para a formação e o desenvolvimento pessoal e profissional do aluno.

As Diretrizes Curriculares Nacionais para o Curso de Graduação em Direito (Brasil, 2004), apontam que o ensino de direito deve assegurar ao aluno uma formação geral sólida, humanística e axiológica, além de desenvolver suas capacidades relativas à análise, ao domínio de conceitos e da terminologia jurídica, à adequada argumentação, à interpretação e à valorização dos fenômenos jurídicos e sociais, conjugando tudo isso a uma postura reflexiva e crítica que o conduza à aprendizagem contínua, autônoma e dinâmica, indispensável ao exercício da ciência do Direito, da prestação da justiça e do desenvolvimento da cidadania.

Desse modo, o curso de Direito deve ser responsável por estimular o raciocínio e a criatividade dos alunos, por exercitar uma visão crítica e formar pessoas conscientes do seu papel na sociedade, para que o profissional, uma vez formado, esteja apto a trabalhar com a complexidade das questões jurídicas. É fundamental, portanto, o estabelecimento de um ponto de partida comum entre professor e aluno, para que seja possível o início de uma caminhada que tenha por objetivo o diálogo necessário à construção do conhecimento e pensamento jurídico.

\subsection{O PROFISSIONAL DOCENTE DO DIREITO}

Muito se tem pesquisado sobre a docência no ensino superior, pois é fato a preocupação com a qualidade do ensino superior no Brasil, o que tem suscitado vários estudos sobre a formação e o desenvolvimento dos profissionais docentes. Essa preocupação, contudo, vai além da formação conteudista desejável pelo mercado de trabalho, pois exige profissionais com formação no campo dos saberes pedagógicos e políticos.

Assim, o professor universitário, além de sua formação teórico-disciplinar, atua como profissional reflexivo e crítico no âmbito de sua disciplina, por meio da pesquisa e da investigação de sua própria atuação. O aperfeiçoamento da docência universitária exige uma integração de saberes complementares e multidisciplinares.

No entender de Anastasiou, Cavallet e Pimenta (2002, p. 212) 
Diante dos novos desafios para a docência, o domínio restrito de uma única área científica do conhecimento não é suficiente. O professor deve desenvolver também um saber pedagógico e um saber político. $O$ saber político dá ao docente, através da ação educativa, a formação de opinião que certamente colabora com a construção da consciência de cada um. Uma vez conscientes, docentes e alunos, fazem-se sujeitos da educação.

De fato, cabe ao docente discutir não só os princípios de aprendizagem que serão norteadores de sua prática, mas também a organização das atividades e disciplinas, os procedimentos e o processo avaliativo a serem usados. Masetto (2003, p. 72), esclarece: "concebe-se o professor como um mediador decisivo entre o currículo estabelecido e os alunos, um agente vivo no desenvolvimento curricular".

Na mesma linha de análise, Basso $(1998$, p. 5) propõe:

A finalidade do trabalho docente consiste em garantir aos alunos acesso ao que não é reiterativo na vida social. Dito de outra forma, o professor teria uma ação mediadora entre a formação do aluno na vida cotidiana onde ele se apropria, de forma espontânea, da linguagem, dos objetos, dos usos e dos costumes, e a formação do aluno nas esferas não cotidianas da vida social, dando possibilidade de acesso a objetivações como ciência, arte, moral etc. e possibilitando, ao mesmo tempo, a postura crítica. (BASSO, 1998, p. 5).

No ensino superior, observa-se que nos últimos anos, os professores universitários começaram a se conscientizar de que sua atuação como docentes exige capacitação própria e específica, que não se restringe a ter um diploma de bacharel, ou mesmo de mestre ou doutor, ou ainda apenas aos anos de experiência de uma profissão. A esse respeito Masetto (2003) destaca:

Docentes de educação superior atualmente devem estar ocupados, sobretudo, em ensinar seus estudantes a aprender e a tomar iniciativas, ao invés de serem unicamente fontes de conhecimento, devem ser tomadas providências adequadas para pesquisar, atualizar e melhorar as habilidades pedagógicas, por meio de programas apropriados ao desenvolvimento de pessoal. (Masetto, 2003, p. 16)

A educação superior assume, também, a atribuição de contribuir para o desenvolvimento da sociedade, sendo de qualidade e respondendo às expectativas dessa mesma sociedade. Isso implica em repensar o saber docente que pode ser definido como um saber plural e compósito (Tardif, 2006), que se forma em conjunto com os demais saberes advindos da formação profissional, curricular e experiencial.

Em suma, o professor ideal é alguém que deve conhecer sua matéria, sua disciplina e seu programa, além de possuir certos conhecimentos relativos às ciências da educação e à pedagogia e desenvolver um saber prático baseado em sua experiência cotidiana com os alunos. (Tardif, 2006, p. 39).

Assim, é importante que se reflita sobre a necessidade da mediação entre o saber específico (conteúdo) e a ação docente (prática). Para Maria do Céu Roldão (2007):

O professor profissional - como o médico ou engenheiro nos seus campos específicos - é aquele que ensina não apenas porque sabe, mas porque sabe ensinar. E saber ensinar é ser especialista dessa complexa capacidade de mediar e 
transformar o saber conteudinal curricular - seja qual for a sua natureza ou nível - pela incorporação dos processos de aceder à, e usar o conhecimento, pelo ajuste ao conhecimento do sujeito e do seu contexto. [...] Saber produzir essa mediação não é um dom, embora alguns o tenham; não é uma técnica, embora requeira excelente operacionalização técnico-estratégica; não é uma vocação, embora alguns a possam sentir. É ser profissional de ensino, legitimado por um conhecimento específico exigente e complexo, de que procuramos clarificar algumas dimensões. (p.102, grifo da autora)

No que se refere ao ensino do Direito, Mello (2007, p. 64), afirma que "de um modo geral, esses professores encaram com naturalidade a evidência de que ensinam Direito por meio da transmissão de conteúdos que aprenderam, sem ter, de fato, aprendido a ensinar".

Em geral, o curso de Direito possui currículos e metodologias de ensino bastante semelhantes, qual seja, baseado na transmissão de conhecimento do professor para o aluno por meio de aulas apenas expositivas e quase nunca dialogadas.

Ademais, existe um estigma de que o bom professor de Direito possui uma profissão consolidada na área jurídica. Os próprios alunos esperam que seus professores já tenham uma carreira jurídica exemplar, como se esse fato, por si só, convalidasse a qualidade como educador. De certa forma, é usual que os docentes utilizem, em sala de aula, exemplos que vivenciam no seu cotidiano jurídico e que isso, por si, pode suprir eventuais falhas didático-pedagógicas dos docentes, sob o entendimento de que une a teoria e a prática.

Desse modo, as instituições devem procurar construir um corpo docente de qualidade, comprometido com o Projeto Político Pedagógico, com profissionais dotados de bom desempenho crítico e reflexivo, que possam empregar técnicas e dinâmicas metodológicas interativas, pois a sala de aula não pode ser um lugar de narração e sim um "palco de debates" (Mello, 2007, p. 64), que irá possibilitar a construção do raciocínio.

Diante dessa possibilidade, nota-se a importância da identidade docente para o professor de Direito. Carlini (2007, p. 338) reforça:

A construção da identidade docente inclui, necessariamente, responsabilidade por todos os aspectos que compõem a formação do aluno, colocando por terra a ideia de que o papel do professor se resume ao seu trabalho em sala de aula, que não Ihe cabe agir intervindo na instituição, na forma de sua organização ou na forma como os alunos são tratados por ela.

É preciso que os professores tenham condições de realizar seu papel no ensino e na aprendizagem e, também, na sociedade, rompendo com os limites estabelecidos em sala de aula e assumindo, efetivamente, a função de agente político e social.

Assim, a profissionalização docente ou a construção da identidade de professor constitui-se numa ação em constante transformação e adaptação, que busca acompanhar os movimentos relativos ao ensino e aprendizagem e refletir sobre sua práxis, na tentativa constante de transformar a educação e melhorar a realidade universitária.

\section{METODOLOGIA DA PESQUISA}


Numa concepção minimalista podemos definir metodologia como sendo um conjunto de técnicas e procedimentos para a coleta de dados da pesquisa, ou ainda o caminho a ser trilhado para que o pesquisador atinja os objetivos pré definidos em seu projeto de pesquisa. (Gonsalves, 2001). Neste trabalho, adotamos uma abordagem qualitativa como perspectiva metodológica por se compreender que esta opção propiciaria uma imersão em maior profundidade na realidade docente e configurou-se como estudo de caso, que é um modo específico de coletar, organizar e analisar dados com o propósito de reunir informações compreensivas, sistemáticas e em profundidade sobre o caso de interesse.

\subsection{Participantes da Pesquisa}

Foram convidados de forma aleatória, dez professores do curso de Direito de uma instituição de ensino superior particular da cidade de Presidente Prudente. O critério da escolha de dez professores adveio do percentual de $20 \%$ do total da população docente do curso de Direito naquela instituição. Não houve nenhuma forma de intervenção hierárquica na escolha dos sujeitos, bem como no decorrer do desenvolvimento desta pesquisa.

A coleta de dados foi realizada por meio de entrevistas, com um roteiro semi-estruturado, gravadas e, posteriormente, transcritas com a autorização expressa dos sujeitos através do TCLE Termo de Consentimento Livre e Esclarecido.

A entrevista, para Lakatos (1985, p. 173)

A entrevista é um encontro entre duas pessoas, a fim de que uma delas obtenha informações a respeito de determinado assunto, mediante uma conversação de natureza profissional.É um procedimento utilizado na investigação social, para a coleta de dados ou para ajudar no diagnóstico ou no tratamento de um problema social."

Procuramos, durante esse processo, obter informações sobre a capacitação destes profissionais, as concepções que eles têm sobre a docência, as práticas pedagógicas utilizadas, suas motivações e as dificuldades para o exercício da docência no contexto daquela instituição de ensino.

Além das entrevistas foram analisados os documentos pertinentes ao Projeto Pedagógico do Curso de Direito - PPC, com o intuito de conhecer suas diretrizes e bases de discussão, em especial no tocante as políticas para o "pensar" e o "fazer" acadêmico.

A utilização de documentos em pesquisa é sempre valorizada e apreciada, haja vista a riqueza de informações que se pode extrair dos documentos, por isso é justificado o uso da análise de documentos na área das ciências humanas e sociais, pois possibilita ampliar o entendimento de objetos cuja compreensão requer uma contextualização.

Acreditamos que o objetivo da análise documental é identificar, em documentos primários, informações que sirvam de subsídio para responder alguma questão da pesquisa. Por representarem uma fonte natural de informação, documentos "não são apenas uma fonte de informação contextualizada, mas surgem num determinado contexto e fornecem informações sobre esse mesmo contexto" (Lüdke \& André, 1986, p.39). 


\subsection{Forma de análise dos resultados}

Os dados obtidos na pesquisa foram trabalhados por meio da análise de conteúdo apresentada por Bardin (2008), que consiste na interpretação do significado das respostas apresentada pelo pesquisado. As fases da análise dos dados, foram organizadas em pólos cronológicos : a pré análise, a exploração do material, o tratamento dos resultados, a inferência e a interpretação. As respostas obtidas dos pesquisados, foram separadas por categorias e relacionadas com os objetivos definidos na pesquisa.

\section{OS ACHADOS DA PESQUISA}

O curso de Direito, na instituição em foco, é composto por 41 docentes, entre os quais, 10 foram convidados, de forma aleatória, a participar da pesquisa. No tocante à formação acadêmica todos os professores concluíram seus estudos em IES privada e apenas professores informaram ter iniciado curso de pós-graduação stricto sensu (Mestrado) na área do Direito em IES pública, sendo que um deles cursa, atualmente, o Doutorado. Dos 10 docentes 8 participaram de cursos de pósgraduação lato sensu em IES privadas. Já na área de Educação, apenas um professor cursou pósgraduação stricto sensu em IES pública, tendo concluído Mestrado e Doutorado.

Com relação à trajetória profissional dos docentes, verificou-se que os mesmos dedicam de 08 a 30 horas semanais à docência e possuem de 11 a 24 anos de magistério no ensino superior. No que concerne à sua inserção no ensino superior verificamos que 7 deles foram convidados diretamente pelo Coordenador do curso. Os professores relataram que, até então, nunca tinham tido qualquer experiência, como pode ser confirmado pelos depoimentos:

[...] eu conclui o curso de Direito e me coloquei à disposição dele (Coordenador), para que assim que surgisse uma oportunidade, eu estaria pronto. E assim aconteceu, eu estava no meu escritório, trabalhando, e ele me convidou. Eu nunca tinha passado por uma experiência desta. Isso era 1998, umas 4 e meia da tarde... ele me perguntou se eu estava preparado, e eu disse que sim. Aí ele disse está muito bem, então nós vamos fazer uma experiência com você hoje à noite, com duas turmas! (rs) eu disse hoje??? Direito Comercial. Eu pensei... eu sou um irresponsável mesmo, porque, na verdade, durante os 4 anos de Direito e não estava preparado nem para o exercício do Direito, quanto mais para dar aulas de Direito! Mas, enfim... fui muito bem recebido por pelos alunos e estou lá até hoje. Então, meu ingresso na carreira docente foi assim, meio abrupto! (P8)

Eu fui convidado pelo diretor da Faculdade de Direito que na época queria incrementar a qualidade do curso, chamando um ou dois juízes e promotores para fazer parte do quadro de professores. Em razão desse convite realizado, por algum tempo, eu comecei a dar aulas, mas não tinha nenhuma experiência anterior. Isso faz 14 anos. (P2)

O meu ingresso na carreira docente se deu quando eu comecei a fazer o mestrado, foram me oferecidas aulas. Havia dado um ano no ensino primário, e não tinha interesse em dar aulas, mas foi o mestrado que me despertou para aceitar o convite de dar aulas em Faculdade, e comecei em 2000. A minha experiência com o primário foi terrível, eu achei muita responsabilidade, achava que eu não estava talhada pra 
aquilo, foi uma experiência difícil, e eu não me motivava a dar aulas, mas acabei mudando de opinião por causa do mestrado. (P7)

Sabe-se que, em geral, os profissionais do Direito, normalmente, exercem outra atividade paralela à docência, como advogados, juízes, promotores. Neste quesito, apuramos que 8 dos docentes exercem, de fato, outras atividades jurídicas e apenas 2 dos docentes entrevistados se dedicam exclusivamente à docência. Questionados sobre o que mais contribui para o aprimoramento e atualização da sua atuação docente, os professores indicaram: cursos presenciais e à distância; experiência de trabalho; intercâmbio com colegas de trabalho; cursos de pós-graduação; eventos na área; leituras por conta própria e internet.

Com base nessas indicações, notamos que se sobressai a "experiência de trabalho", exercida em fóruns e tribunais, como fundamental para o aprimoramento da prática docente. Essa ideia, a nosso ver equivocada, vem reforçar a tese de que, para alguns professores de Direito, a experiência forense basta para o aprimoramento da prática docente.

\subsection{Os professores e a sua identidade docente}

Para compreender a identidade docente consideramos as concepções que os professores têm sobre a docência sob o aspecto do entendimento, forma de organização e compreensão de suas experiências e vivências e, principalmente, o conceito que eles imprimem sobre a função do professor.

Segundo Thompson (1997 apud Figueiredo, 2007, p. 40) "[...] as concepções dos professores incluem suas crenças, visões e preferências sobre o conteúdo e seu ensino, que desempenham papel importante no que se refere a sua eficiência como mediadores primários entre conteúdos e alunos".

Sabemos que, atualmente, a identidade do professor passa por uma reconstrução e um dos componentes dessa nova identidade são as competências profissionais, pois além dos saberes ou conhecimento, os professores devem ter também o chamado "skills" é a atitude para aplicar os saberes de maneira efetiva e que traga bons resultados (Bolivar, 2002).

Neste contexto considerando-se, entre outros fatores, a formação permanente como forma de reconstrução da identidade do professor, temos os seguintes depoimentos:

A primeira coisa que eu procuro fazer é afastar qualquer desnível entre aluno e professor, porque já existe um natural receio do aluno em se aproximar do professor, em perguntar, questionar... existe um certo temor reverencial do aluno, isso é muito comum, e se o professor acentua isso, ele acaba dificultando a comunicação com o aluno. $O$ ensino é uma forma de diálogo, comunicação, de recepção e transmissão de mensagens e, evidentemente, quanto mais aberto for esse canal de comunicação, quanto maior for o diálogo, quanto mais facilidade o aluno tiver de se aproximar, de questionar, de criticar, enfim de se comunicar com o professor. (P3)

O professor deve ser muito estudioso, deve ser metódico, deve se atualizar sempre, eu sempre digo que o professor não pode dar a aula seguinte da mesma forma que ele deu a anterior. Ele tem que administrar as diferenças de classes sociais, de etnias, de idade, tem gente de 18 anos e 60 anos, e, claro, com objetivos completamente 
diferentes. $O$ professor tem que ter essa habilidade e procurar fazer um nivelamento. Ele também tem que ter critérios de avaliação, e não puramente cobrar do aluno o conhecimento memorizado. (P5)

Olha, o bom professor de Direito precisa ter formação pedagógica; porque como eles vão entender, por exemplo, sobre a avaliação se eles nunca leram autores que falam sobre esse tema... como eles vão pensar didática, como vão pensar currículo, se eles nem imaginam o que é isso. A gente vê que a maioria dos professores de Direito que não tem essa formação pedagógica, veem a avaliação como punição, como um momento único. É difícil para um professor de Direito, sem formação pedagógica, se colocar como aluno, ele tem que entender que o aluno precisa entender a importância daquele conteúdo na sua vida cotidiana, na sua vida profissional. (P 10)

Além disso, para ensinar bem, não basta simplesmente conhecer a matéria ou estar sempre atualizado. $O$ estabelecimento de uma relação com base no entendimento e respeito pelos alunos, pelo meio e cultura de onde eles provêm, associados à compreensão, amizade, consideração, é que devem gerar novas atitudes estratégicas. A atitude de cada um reflete em uma marca pessoal de cada docente perante os alunos.

Em relação à marca registrada... eu acho que a presença dos alunos é o melhor termômetro. O silêncio também é um ponto importante, dá pra dosar o interesse pela aula. Outra coisa são as homenagens que você recebe durante sua vida docente. Isso é reconhecimento, acho que é uma forma de avaliar a qualidade do professor. Eles até perguntam por que eu acho que a aula de Direito é muito teórica. E também eu não sento, e também mudo o tom de voz sempre. Os exemplos que dou são sempre chocantes para atrair a atenção deles. Essas são minhas marcas! (P4)

Minha marca, eu acho que é... bem, eu gosto de trabalhar com o aluno e gosto de trabalhar desde o primeiro ano, de pegar na mão, de ensinar a estudar... de ensinar como ele deve aprender a estudar, dar a base, ensinar como deve se estudar no curso de Direito, quais são as prioridades, de que forma ele deve estudar, eu gosto do primeiro ano por isso. Quando eu fiz o curso de Direito, eu notei essa deficiência, o professor nunca dizia como você precisava estudar, como se deve iniciar uma pesquisa... eu começo dizendo que o aluno deve sempre estudar tendo um bom dicionário por perto, estudar a lei, a doutrina... ensinar o aluno a estudar a doutrina, é isso. (P9)

Sabemos que a docência, em todas as esferas, lida também com um aspecto delicado do ser humano, que é o caráter. É certo que a ação do professor promove exemplos, mudança de hábitos, costumes e até valores. "A educação é um dos fatores de formação da consciência moral, que se pretende autônoma e livre" (Estrela, 1997, p. 163).

Outra questão relevante, quando se fala sobre a "marca registrada" dos bons professores, se concentra, especificamente, na formação pedagógica dos mesmos. São professores que estimulam a criatividade, buscam sempre integrar ensino e pesquisa e transmitem conhecimento de modo muito pessoal, por meio do conhecimento didático. Portanto, temos que a 
complementação pedagógica na formação do professor de Direito proporciona um grande diferencial, que é indubitavelmente flagrado pelos alunos.

Minha marca é ser pedagoga, essa é minha marca. Isso faz toda a diferença, os alunos percebem. Hoje, por exemplo, foi muito engraçado, porque eu falei para os alunos: vamos fazer uma roda para debater os casos práticos que vocês trouxeram sobre a matéria da aula passada, e eles disseram "ah! professora, isso é coisa de pedagoga". E também tem outra coisa, o professor que é pedagogo, sabe que precisa estar em constante aprimoramento, estar atualizado, então eu colocaria outras marcas registradas minhas: ser pesquisadora, ser autora e ser pedagoga. Você reconstrói seu conhecimento a cada aula, a cada nova experiência. (P10)

Os depoimentos revelam que a profissão docente abrange singularidades que a diferenciam das demais profissões, ou seja, não basta apenas carregar um título acadêmico, é preciso o comprometimento do profissional professor que esteja disposto a refletir, aprender, mudar. Acreditamos, ainda, que para se compreender a identidade profissional do professor, é necessário que se pense na ligação existente entre a profissão professor e sua função social, tendo em vista que os movimentos sociais possuem íntima relação com os projetos educacionais. Para Freitas (2005, p. 73), "a função social da escola se cumpre na medida da garantia do acesso aos bens culturais, fundamentais para o exercício da cidadania plena no mundo contemporâneo". Assim, para garantir uma formação satisfatória do aluno em face do mundo globalizado, é imprescindível que o professor se atualize, repense as teorias de sua formação, a fim de dar melhor suporte à sua prática pedagógica atual.

\subsection{Organização do Trabalho Pedagógico em sala de aula}

Entende Veiga (2008, p. 268):

Como é de se supor, a organização de um processo tão complexo como a aula não pode resultar de um movimento mecânico e simplista. A aula não pode ser pensada como um receituário ou uma ação improvisada em torno de um tema.

Acompanhamos a autora, pois a organização prévia da aula, o seu planejamento adequado, tem o condão de evitar improvisações das tarefas docentes que, em geral, levam a efeitos questionáveis. O planejamento da aula deve estar em consenso e devidamente articulado com o Projeto Pedagógico do Curso, que por sua vez deve estar de acordo com o Projeto Político da Instituição. É certo afirmar que a sala de aula é um espaço físico, no qual a aula é uma construção histórica de conhecimentos, com muitos significados. Portanto, a aula precisa ser objeto de organização e planejamento.

Eu tenho um planejamento. Eu tenho as matérias nos termos que eu dou aulas, divididas por aulas, eu sempre forneço aos alunos livros específicos daquele tema que trato em aula, também forneço aos alunos textos, doutrinas, que vejo na internet, trabalhos que vejo em teses de mestrado e doutorado, que acho que é bom, para que eles, além do básico. (P2) 
Todo o professor de Direito, parte de um período de planejamento escolar que é determinado pela Faculdade. Ele tem um plano de ensino que tem que estar atrelado ao Projeto Pedagógico do Curso e a ementa daquela disciplina. De posse de tudo isso ele elabora um cronograma de aula e a bibliografia básica $e$ suplementar que vai usar. E a nossa coordenação exige de nós professores que no primeiro dia de aula apresentem e disponibilizem aos alunos, para que possam acompanhar a sequência daquele plano. Já existem todas as diretrizes previamente traçadas e a coordenação vai acompanhando. (P5)

Além do planejamento, seleção e organização da aula, é preciso atentar para as necessidades de formação dos alunos, aproveitar fatos da vida sócio-política e verificar a quem interessa a propositura de algumas atividades e informações.

Bom, existe um planejamento, os temas são pré-definidos, mas, além disso, eu costumo fazer a partir do perfil da sala, porque cada sala tem um perfil diferente. Procuro planejar as minhas aulas de acordo com o perfil de cada turma. Então, nas salas onde existem alunos que participam das aulas, eu estimulo a participação deles. Apresento problemas do dia a dia, sugiro debate entre eles, apresento questionamentos, faço brincadeiras, etc. Outras salas em que eu noto que o perfil é mais contido, aí preponderam as aulas expositivas. Mas eu procuro sempre fazer com que o aluno participe. (P3)

Os professores, ao organizarem sua aula, devem considerar a intencionalidade de seu planejamento, situando-se como protagonistas da aula e sujeitos de suas ações pedagógicas. Para Veiga (2000, p. 9), "as técnicas de ensino adquirem significado quando referenciadas a um projeto político pedagógico que expresse de que escola falamos, a que ensino nos referimos e por qual transformação social estamos lutando".

Alguns professores, ao serem questionados sobre quais as metodologias de ensino que utilizam em sala de aula, relataram:

A aula de Direito é bem expositiva, não tem jeito. Embora alguns professores usem vídeo, retroprojetor... na minha disciplina, como tem muito conteúdo, eu não posso perder tempo em ficar expondo vídeos, por exemplo, eu tenho que esgotar o conteúdo. Então, eu passo os tópicos na lousa, os tópicos que a gente vai desenvolver pra que eles fixem o conteúdo, e quando é importante, eu dito alguns conceitos para não ter que passar na lousa, eu dito. (P6).

Eu tenho um sinótico, um esquema, um roteiro da aula, que eu gosto de passar na lousa... porque eu sempre aprendi mais com meus professores que entravam em sala e colocam alguma coisa na lousa, e seguiam... passavam o resumo na lousa... eu sou meio metódica, eu gosto de seguir aquela orientação. (P9).

Verifica-se que ainda persistem ações que certamente desmotivam o aprendizado por parte dos alunos. Se o professor é criativo em sua prática, pode-se concluir que também terá condições mais adequadas de desenvolver a criatividade em seus alunos.

Quando o assunto versa sobre a avaliação, verificamos que forma de avaliação utilizada por alguns professores ainda é bastante tradicional, sem muita criatividade, não possibilitando o 
diagnóstico das dificuldades apresentadas pelos alunos. Para alguns professores pesquisados, a avaliação restringe-se a um instrumento estático, de cunho apenas classificatório. $O$ ato de avaliar posto dessa forma não serve como pausa para pensar a prática e retornar a ela modificando-a. A avaliação no curso de Direito tem tido como indicador da aprendizagem a reprodução automática e sem vacilo, pelo aluno, do conteúdo das aulas dadas pelo professor (Arnoldi \& Oliveira, 2002, p. 51). Os relatos abaixo indicam nossa reflexão:

Se eles forem um pouquinho dedicados e esforçados, respondem o questionário e vão aprender um pouco mais sobre o tema. E serve para a nota, como forma de avaliação. Em termos de avaliação eu divido a nota em duas partes, nota bimestral $e$ esses trabalhos que eles fazem complementam a nota. (P2)

Faço as avaliações através das provas, mas não gosto de perguntas objetivas, gosto que os alunos façam uma dissertação sobre algum tema. Faço também debates entre eles, que estimulam o aprendizado, com assuntos atuais. (P4)

Quanto à avaliação, ela é feita na prova... é estudar a doutrina e fazer a prova, porque não sou eu que determino as questões que eu faço na prova, mas eu estou sempre me atualizando, vendo o que está sendo pedido no exame da $O A B$, então eu trago para os alunos aquelas questões que são elaboradas para o exame da Ordem, e que são relevantes, e coloco também na prova. (P9)

Pensando na relação entre planejamento e avaliação, apontamos, ainda, a seguinte definição: "enquanto o planejamento é o ato pelo qual decidimos o que construir, a avaliação é o ato crítico que nos subsidia na verificação de como estamos construindo o nosso projeto" (Luckesi, 2006, p. 118). Sendo assim, a avaliação permeia todo o ato de planejar e de executar e, desta forma, contribui em todo o percurso da ação planejada. Portanto, a avaliação é necessária para a construção crítica de um percurso, pois além de avaliar, pode detectar obstáculos e propor mudanças. Assim, transformar a prática avaliativa significa questionar a educação desde as suas concepções, seus fundamentos, sua organização, suas normas. Deve ser contínua, formativa no que se refere ao desenvolvimento do aluno, na sua totalidade.

Igualmente interessante é a visão que considera a avaliação como um ato ético e moral. A avaliação deve ser praticada para analisar o que os alunos aprenderam, o que ainda lhes falta aprender e o que precisa ser modificado, de modo a contribuir para o desenvolvimento da sua aprendizagem (Villas Boas, 2000). A autora reforça que a avaliação da aprendizagem deve envolver, além da análise do trabalho do professor, uma autoavaliação do próprio aluno sobre seu desempenho, por meio do qual ele possa refletir de forma honesta e sincera sobre seu próprio processo de aprendizagem. Trata-se da avaliação formativa. Neste contexto, destacamos o seguinte depoimento:

As pessoas, às vezes, ficam surpresas com a minha postura. .No curso de Direito eu trabalho com autoavaliação, a cada semestre eu aplico uma autoavaliação, então o aluno tem que falar o que ele aprendeu naquela disciplina, como ele relaciona aquela disciplina com o seu cotidiano, como ele relaciona aquela disciplina com outra disciplina, e o que ele achou das aulas, como poderia ser melhorada, etc. Isso é uma coisa que os professores de Direito não fazem. (P10)

Observamos que alguns professores se pautam apenas por seus próprios saberes, imaginando que seus saberes, por si só, podem ser formadores. Cremos que saber sobre algum assunto e colocar na lousa ou ditar para os alunos, não é suficiente, é preciso ir além, é preciso saber ensinar, envolver, surpreender os alunos. 
O saber apenas transmitido não possui nenhum valor formador, nas palavras de Tardif (2006, p. 44), "os mestres assistem a uma mudança na natureza de sua mestria: ela se desloca dos saberes para os procedimentos de transmissão dos saberes". Ou ainda: "de forma um pouco caricatural, poder-se-ia dizer que o ato de aprender se torna mais importante que o fato de saber" (2006, p. 45).

\subsection{Formação e atualização pedagógica na prática docente}

No decorrer deste trabalho de campo, procuramos ouvi-los sobre a importância da formação e atualização pedagógica para a prática docente. Transcrevemos abaixo trechos das entrevistas que, por si só, são esclarecedores.

Sim. Porque só assim você pode compreender o seu ato e até onde ele vai... porque você... na verdade, eu não tenho a capacitação pedagógica porque eu não tenho o título, mas eu vi muitos seminários que envolviam essa matéria, a pedagogia, e fiz o curso de especialização e avaliação de ensino e aprendizagem, que a própria Universidade oferece. (P1)

Sem dúvida que sim, eu acho importantíssimo porque eu acredito que mesmo com formação pedagógica, a tarefa docente é difícil, é uma arte. E se você vai despreparado, desarmado para essa batalha, fica muito mais difícil. Então, para mim, é óbvio que uma formação pedagógica seria extremamente útil, para qualquer área. (P3)

Eu digo que é indispensável! O professor moderno não poderia ser "atirado às feras" sem antes passar por um treinamento, um curso de capacitação, esse curso teria que ter técnica de didática, avaliação, conceitos de dinâmica, metodologia. Antes de dar aulas, o professor teria que se capacitar. (P5)

Algum tipo de capacitação tem que ter... não sei se na linha da pedagogia, mas alguma coisa... o problema de se exigir um curso de capacitação em pedagogia, é ficar abrangente demais e desinteressar o profissional do Direito, um juiz, um promotor que venha ministrar aula de conteúdo específico, não sei se terá interesse em fazer um curso de pedagogia. Ás vezes a Faculdade consegue disponibilizar palestras de pedagogos a cada início de semestre, nosso coordenador tem um estilo bem pedagógico, ele nos incentiva muito.... Eu não fiz nada em educação, parei para terminar o curso de Direito, mas principalmente com relação à metodologia, ... é preciso ter conhecimento em educação para poder fazer melhor. (P6)

Eu acho importante. Eu fiz um curso em SP e tinha um professor tributarista, famoso, ele entendia muito de Direito Tributário, mas ele não tinha didática nenhuma, então a aula dele era maçante, monótona... o professor tem que ter didática, não adianta... sem isso ele não consegue... ele pode até transmitir o conteúdo, mas não consegue o que é essencial,. O professor é um formador de opinião, vai formar pessoas. (P7)

De certo modo, é fácil depreender a importância da formação pedagógica para o docente do Direito, visto tratar-se de um curso com forte tradição nas aulas expositivas, que está associada à postura passiva dos alunos, o que certamente dificulta a implementação de ações mais criativas que acenem para sua participação. 
Para Veiga (2000) muitos professores podem apresentar muito bem o conteúdo, mas desconhecem procedimentos que levem o aluno a ter autonomia intelectual e construir sua própria aprendizagem. E o professor, protagonista neste cenário, não pode se abster.

Urge pensar numa nova forma de ensinar e aprender que inclua a ousadia de inovar as práticas de sala de aula, de trilhar caminhos inseguros, expondo-os, correndo riscos, não se apegando ao poder docente, com medo de dividi-lo com os alunos e também de desvencilhar-se da racionalidade técnica e pôr em ação outras habilidades que não as cognitivas apenas. Pensar-se como participante do desvelamento do mundo e da construção de regras para viver com mais sabedoria e com mais prazer. (Veiga, 2000, p. 87).

Ademais, concordamos com a ideia de que o ensino-pesquisa seja também um procedimento metodológico, como defende Balzan (2000) ao afirmar que a pesquisa como forma de ensinar oferece a possibilidade da consciência cristalina de que sua formação nunca será finita. O autor reforça que "a articulação ensino-pesquisa é necessária para que se alcance um ensino de alta qualidade ou, se preferirmos, em nível de excelência". (p. 118)

\subsection{Dificuldades para o exercício da docência}

Neste item, os depoimentos foram agrupados em duas categorias de análise. A primeira categoria (1), diz respeito às dificuldades metodológicas e didáticas relacionadas pelos professores dentro de sala de aula. Já a segunda categoria (II), refere-se às dificuldades pessoais encontradas no exercício da sua ação docente.

\subsubsection{Dificuldades metodológicas}

O professor exerce uma atividade que intervém na realidade social e nesse sentido, a sua prática pedagógica precisa ser uma opção consciente revestida em transformação, renovação, na busca de melhorias para a sociedade e com oportunidades para todos. Essa prática pode ser vista como fonte de conhecimento, assim, o "novo" deve ter sempre um papel importante na ação docente.

Observamos que parte das dificuldades apontadas pelos docentes se refere às questões estruturais, como uso de material de informática, ou mesmo dificuldades para a solicitação ou agendamento do uso deste material.

Tenho também dificuldade com computação, e-mail, eu sei digitar, mas não sei programar, não sei formatar, etc. Usar essa parafernália, o tempo foi passando e eu fui ficando atrasado... eu poderia estar dando aulas com notebook, com projetor, mas por outro lado, nós não temos aqui apoio da Faculdade pra usar isso... Aqui você tem que falar antes, reservar, eu acho que esse material teria que estar na sala de aula disponivel para usar ou não. (P1)

A dificuldade que eu vejo, no meu atual momento, é que a Faculdade está passando por uma transformação tecnológica. Como eu tenho uma outra atividade que me ocupa muito tempo, eu acabo sofrendo com essa informática que não funciona... se você abrir o notebook na sala de aula, ele não funciona, não é fácil... e aí você 
acaba tendo um conflito. Mas minha maior dificuldade seria essa, acompanhar a tecnologia! (P2)

Outra questão que merece destaque por parte dos professores entrevistados, diz respeito à aparente falta de interesse dos discentes.

O exercício da atividade do profissional de Direito, é o exercício da comunicação, ele trabalha com o ordenamento jurídico e com a língua portuguesa, e há uma tendência, até por conta da internet, dessa linguagem cifrada, reduzida... há uma dificuldade hoje do aluno de trabalhar com o vernáculo, com a língua portuguesa e isso tem gerado dificuldades. Porque numa conversa informal, num e-mail, você pode falar de uma forma reduzida, mas isso num contrato, numa petição, pode comprometer todo o trabalho e gerar várias consequências danosas. (P3)

Algumas dificuldades estão relacionadas ao interesse dos alunos, hoje, a parcela que tem realmente interesse é muito pequena. Eu vivo falando, vocês são privilegiados porque fazem um curso superior, mas acho que só uns $30 \%$ da classe se interessa de verdade. (P4)

A falta de tempo para planejar e elaborar as aulas, também mereceu destaque por parte de dois dos docentes entrevistados.

A minha experiência na docência é no curso de Direito, e no curso de Direito nós temos advogados professores, então o advogado, ele chega no escritório cedo e sai o mais tarde que ele pode, durante o dia ele tem que atender clientes, elaborar peças, ir ao fórum ver o processo, ir nas audiências, viajar. Então o advogado, que nas horas vagas também é professor, tem essa grande dificuldade... de não termos um professor mais voltado para a docência, com mais dedicação à docência. (P5)

Eu gostaria se pudesse me dedicar mais à docência... gostaria de ter mais tempo... a dificuldade que eu vejo é o pouco tempo que eu dedico. (P8)

Consideramos importante destacar que o planejamento deve ser compreendido como um processo de reflexão que tem como intuito principal propiciar o despertar do sujeito sobre a necessidade de mudanças e capacitá-lo para atingir suas metas. Acreditamos que planejar a aula é um compromisso com a docência, é uma forma de imprimir respeito ao que se faz em sala de aula.

A necessidade da extensão do quadro curricular do curso também foi abordada. 0 professor manifestou preocupação com o aumento da abrangência do Direito, como ciência e as novas demandas geradas por conta dessa expansão. O professor relata, ainda, que o curso poderia ser feito em cinco anos, e não quatro anos como é atualmente.

"É preciso destacar quais os conceitos mais gerais e inclusivos, quais os conceitos subordinados de um corpo de conhecimento e de como todos esses conceitos estão organizados, estrutura e hierarquicamente." É preciso ser capaz desta distinção para trabalhar os conteúdos e não é fácil. (Moreira, 1982, p.22) 


\subsubsection{Aspectos pessoais}

É importante perceber que as dificuldades metodológicas dizem respeito às deficiências pessoais, geralmente relacionadas à formação. Esse é o primeiro passo para a reflexão da práxis, sob uma ótica crítica, com o objetivo de transformar realmente a prática docente. Isso nos remete à formação do saber docente que não é formado apenas da prática cotidiana, mas fundamentalmente pelas teorias da educação.

No entanto, poucos foram os docentes que relacionaram suas dificuldades metodológicas detectadas em sala de aula, com a falta de formação pedagógica ou com a falta de ensinamentos ligados à educação, especificamente. Percebemos essas dificuldades de modo indireto quando falam que não tem dificuldades, de que seria bom estudo da avaliação e quando dizem que o currículo é extenso. Percebe-se a ausência da identidade profissional docente.

Uma segunda dificuldade que eu acho é a prática, eu acho que a prática de estágio deveria ser maior, mais incentivada. Os alunos saem com a teoria, mas sem prática... e eu não sei como motivá-los. (P4)

O professor não está comprometido com a docência e acha que vem aqui dá o recado e vai embora. O grande problema é a falta de identidade do professor, fica parecendo que ser professor, como se diz na gíria, é um "bico". (P5)

Olha eu não tenho muitas dificuldades não... não lembro de nenhuma que seja relevante... às vezes, o cansaço físico. Trabalho o dia todo e depois ainda tenho que dar aulas, eu penso como vai ser a aula hoje... mas quando eu entro em sala de aula, eu esqueço do cansaço... acho que é o contato! (P7)

Assim, acreditamos que quanto mais criticamente se exerça a capacidade de ensinar, mais se constrói o desenvolvimento da curiosidade por parte do aluno, que certamente proporcionará a si mesmo a busca pelo saber, ou seja, a busca pelo conhecimento.

A questão econômica vem à baila, de forma tímida, por parte de apenas um docente. Faz parecer que o reconhecimento financeiro não importa, quando o assunto é o "santo sacerdócio" da profissão professor. Porém, quando o tema se refere especificamente ao reconhecimento, temos depoimentos mais contundentes.

A dificuldade econômica... mas vejo que essas dificuldades não são só minhas, elas são coletivas. (P1)

Tem dificuldades... muitas vezes as Universidades engessam a atuação docente, por exemplo: com a tal da semana de prova. Tem as dificuldades estruturais, falta de equipamento, até algumas dificuldades no sentido das pessoas entenderem o que estamos fazendo... por exemplo, quando a gente faz um roda na aula de Direito, algumas pessoas não entendem a necessidade disso, quando passo um filme, alguns devem dizer ... ah tá matando aula... então, isso é difícil. Às vezes, a gente não é reconhecido nesse sentido. (P10)

As dificuldades pessoais dos professores entrevistados revelaram lacunas na formação desses docentes, não sob o ponto de vista técnico jurídico, mas sob a ótica dos conceitos formativos relativos à educação. Isso nos remete aos saberes docentes que, segundo Tardif (2006), são um amálgama de saberes da formação profissional inicial, saberes das disciplinas, 
saberes curriculares e saberes da própria experiência, tanto profissional quanto de vida. Saberes esses que devem integrar uma formação que supere o modelo transmissão-recepção.

\subsection{Motivações para o exercício da docência}

A dimensão motivadora do professor abrange vários fatores que não dizem respeito somente a ele, mas também a cada um dos alunos como indivíduos únicos. O professor precisa ser capaz de criar nos alunos uma forte motivação que lhes permita uma boa aprendizagem, além de oferecer-Ihes os meios necessários para que eles possam pensar por si próprios. Para Freire (apud BENCINI, 2001, p. 32), a dimensão política da profissão é o maior motivo para escolhê-la: "A certeza de que faz parte de sua tarefa docente não apenas ensinar conteúdos, mas também ensinar a pensar certo".

Para a maioria dos professores entrevistados os motivos para escolher a profissão docente resumem-se nas seguintes categorias: amor, necessidade de atualização, aprendizagem com os alunos, participar da formação de um ser humano, participar do processo de construção do saber e reconhecimento por parte dos alunos. E, este último, foi enfatizado em grande parte das respostas.

Minha maior motivação são os olhos deles... eles podem não gostar da matéria, mas eles me olham com muito carinho [...] para todo lado que eu vou eu encontro alguém pra quem já dei aula, todo mundo me conhece, então você se sente amado pelas pessoas. (P1)

Eu acho que não tem preço você saber que participou da formação de um ser humano, acho que essa é minha maior motivação... porque o que eu ensino vai além da matéria do conteúdo, eu, em sala de aula, tenho que ser um exemplo. (P4)

Então, minha motivação é ser professor, transmitir conhecimento, eu tenho consciência da importância da docência, é gratificante participar desse crescimento do aluno. Isso é motivador. O que me motiva é o processo de construção. (P5)

As minhas motivações são os alunos... é realmente cumprir essa missão de acreditar que meus alunos serão pequenas sementes que, no futuro, irão fazer a justiça, é bom ver o desenvolvimento deles, o interesse pela justiça. É bom ver o resultado imediato daquilo que você planta a cada dia. (P10)

Percebemos que a maior fonte de satisfação do professor, tem sido ensinar. Contudo, observamos outras fontes de satisfação, como o relacionamento com os alunos, as oportunidades de aprendizagem mútua, o crescimento pessoal e profissional por meio do ensino, e tantas outras recompensas que levam os profissionais a continuarem a exercer a carreira docente.

Corroboramos com a ideia de que sentir-se professor ou assumir-se como professor é o resultado de um processo evolutivo, construído dia a dia e ao longo dos anos, desde o momento da opção pela profissão docente, à custa, fundamentalmente, de um saber experiencial, resultante do modo como os professores se apropriam dos saberes de que são portadores e que deverão reconceitualizar; da capacidade de autonomia com que exercem a sua atividade; e do sentimento de que controlam o seu trabalho (Nóvoa, 1991). 


\section{CONSIDERAÇÕES FINAIS}

A presente pesquisa propôs conhecer a concepção que os professores de Direito têm sobre a docência, sobre suas práticas pedagógicas utilizadas em sala de aula, organização, planejamento e desenvolvimento pedagógico, suas dificuldades e motivações para a ação docente. É interessante destacar que todos os professores entrevistados, que responderam positivamente ao convite proposto, ficaram entusiasmados com a possibilidade de participar de um (re)pensar de suas próprias práticas docentes.

Pudemos observar que os docentes reconhecem a impossibilidade de formar profissionais prontos e acabados, e que refletir sobre tal aspecto pode aliviá-los da suposta obrigação de formar profissionais que darão conta de todas as situações futuras. Especialmente porque o trabalho dos profissionais docentes tem como objetivo, contribuir para a formação de seres humanos, que, por natureza, são seres inconclusos, sempre inacabados. Formar o profissional e a pessoa.

De outro lado, a insatisfação geral com a qualidade no ensino jurídico brasileiro é um fato. As discussões que surgem e se amontoam abordam os mais variados aspectos dessa crise. 0 sistema de ensino jurídico, de forma geral, não tem conseguido superar problemas básicos e muitos já se preocupam com os desafios que as novas gerações enfrentarão por causa disso.

Desta forma, os estudos levam a crer que a qualificação pedagógica específica do professor de Direito pode fazer a diferença em sala de aula, gerando um melhor aproveitamento da aprendizagem no processo educacional.

Os depoimentos revelaram, também, que é preciso que as instituições de ensino se conscientizem da necessidade de investir tempo, esforços e recursos em programas que visem à capacitação e ao desenvolvimento de seus recursos humanos. No entanto, alguns pesquisados não se mostraram conscientes de suas práticas conservadoras e, como consequência, perpetuam a existência de metodologias ultrapassadas nas suas ações docentes diárias.

Assim, na análise dos depoimentos, mostrou-se necessário o preparo específico para o exercício da docência, não bastando, simplesmente, ter conhecimento dos conteúdos a serem ministrados, mas ter didática e saber usar metodologicamente os recursos disponíveis à atuação em sala de aula, visando ao aprendizado significativo para o aluno, por meio de aulas que proporcionem reflexão dos conteúdos apresentados, com problemas do cotidiano e com referência a disciplinas que intervenham na formação do profissional do Direito.

Acreditamos que a identidade do docente jurídico deve ser entendida como aquele profissional que, independente da atividade que exerça em outras carreiras jurídicas, compreenda a docência como uma dedicação exclusiva. Para isso, certamente será desejável que o mesmo esteja em constante atualização, priorizando a adequação de sua prática docente e respeitando o relacionamento entre aluno e professor.

O professor do Direito que agregar à sua atuação características de cunho pedagógico, certamente estará construindo a identidade de educador e de profissional atuante em sua carreira, trazendo confiança para os alunos e para a Instituição em que trabalha.

Evidentemente que permanece o desafio, tendo em vista que o professor de Direito deve estar preparado para estimular a disseminação de um saber jurídico científico, crítico, ético e humanista, que torne o profissional do Direito apto a enfrentar as demandas de um mundo 
globalizado, mas não se descuidando de promover a consciência para o exercício da cidadania, da democracia e para a defesa dos ideais de justiça.

Este estudo nos levou a considerar que essa mudança, de forte teor qualitativo, somente será possível quando o profissional desenvolver competências, ou seja, capacidade de mobilizar recursos cognitivos visando abordar uma situação complexa como a docência, poderá ocorrer uma transformação da formação e da atuação do docente jurídico.

\section{REFERÊNCIAS}

Anastasiou L.G.C., Cavallet VJ., Pimenta S.G. (2002). Docência no ensino superior: Construindo caminhos. In: Fazenda I.C.A, Severino A.J. (Orgs.). Formação docente: rupturas e possibilidades. Campinas: Papirus. p. 207-222.

Arnoldi P.R.C., Oliveira J.R. (2002).O ensino Jurídico baseado na tarefa-problema. Prática Jurídica. $1(1)$.

Balzan N.C. (2000). Indissociabilidade ensino pesquisa como princípio metodológico. In: Veiga I.P.A., Castanho M.E.L.M.C. (Orgs.). Pedagogia universitária: a aula em foco. Campinas: Papirus. p. 115-118.

Bardin L. (1997). Análise de conteúdo. Lisboa: Edições 70.

Basso I.S. (1998). Significado e sentido do trabalho docente. Caderno CEDES. 19(44).

Bencini R. (2001). Dez motivos para ser professor. Revista Nova Escola, N. 146.. Recupaerado de http://www.ensino.net/novaescola/146_out01/html/repcapa.htm.

Bobbio N. (1988). Liberalismo e democracia. São Paulo: Brasiliana.

Brasil. Lei no 9.394, de 20 de dezembro de 1996. Estabelece as Diretrizes e Bases da Educação Nacional. Recupedado de : http://download.rj.gov.br/documentos/ 10112/452097/DLFE31650. pdf/LEIN9394DE20DEDEZEMBRODE1996.pdf

Brasil. Portaria no 1.886, de 30 de dezembro de 1994. Fixa as diretrizes curriculares e o conteúdo mínimo do curso jurídico. Recuperado de:

http://www.oab.org.br/Content/pdf/LegislacaoOab/LegislacaosobreEnsinoJuridico.pdf.

Brasil. Resolução CNE/CES no 9, de 29 de setembro de 2004. Institui as diretrizes curriculares nacionais do curso de graduação em Direito e dá outras providências. Diário Oficial da União, Brasília, 01 out. 2004. Recuperado de:

http://portal.mec.gov.br/cne/arquivos/pdf/rces09_04.pdf.

Carlini A.L. (2007). O Professor de Direito: Perspectivas para a construção de uma identidade docente. In: Almeida Filho J.C.A., Carlini A., Cerqueira D.T. (Orgs.). 180 anos do ensino jurídico no Brasil. Campinas: Millennium. p. 321-341.

Estrela M.T. (1997). Viver e construir a profissão docente. In: Silva M.L. A docência é uma ocupação ética. Porto: Porto Editora.

Fazenda I.C.A. (1995). Interdisciplinaridade: um projeto em parceria. 3. ed. São Paulo: Loyola.

Fazenda I.C.A. (2013). Interdisciplinaridade: história, teoria e pesquisa. São Paulo: Papiros. 
Figueiredo A.C. (2007). Saberes e concepções de Educação Algébrica em Curso de Licenciatura em Matemática. Tese (Doutorado em Educação Matemática) - Programa de Pós Graduação em Educação Matemática, Pontifícia Universidade Católica de São Paulo, São Paulo.

Freitas L.C. (2005). Mudanças e inovações na educação. 2. ed. São Paulo: EDICON.

Gomes L.F. A (2003). Crise (tríplice) do ensino jurídico. Revista Jurídica UNIGRAN, Dourados, MS, jul./dez. recuperado de : http://www.mundojuridico.adv.br/ sis_artigos/artigos.asp?codigo $=414$

Gonsalves E.P. (2001). Iniciação à pesquisa científica. Campinas: Alínea.

Kelsen H. (2003). Teoria pura do direito. Tradução de João Batista Machado. São Paulo: Martins Fontes.

Lakatos E.M. (1985). Fundamentos de metodologia científica. São Paulo: Atlas.

Luckesi C.C. (2006). Avaliação da aprendizagem escolar. 18. ed. São Paulo: Cortez.

Lüdke M., André M.E.D.A. (1994). Pesquisa em educação: abordagens qualitativas. São Paulo: EPU.

Martins F.P. (2005). O positivismo como obstáculo à interdisciplinaridade no ensino jurídico. jun. 2005. Recuperado de: http://www.direitonet.com.br/artigos/ exibir/2116/O-Positivismocomo-obstaculo-a-interdisciplinaridade-no-ensino-juridico

Masetto M.T. (2003). Competência pedagógica do professor universitário. São Paulo: Summus.

Mello R.I.C. (2007). Ensino Jurídico: formação e trabalho docente. Curitiba: Juruá.

Moreira M.A., Masini E.F.S. (1982). Aprendizagem Significativa: a teoria de David Ausubel. São Paulo: Moraes.

Nóvoa A. (1991). Profissão professor. Porto: Porto Editora.

Roldão M.C. (2007). Função Docente: natureza e construção do conhecimento profissional. Revista Brasileira de Educação, 12(34).

Santos A.L.L. (2002). Ensino jurídico: uma abordagem político-educacional. Campinas: Edicamp.

Streck L.L. (2007). Hermenêutica e ensino jurídico em terrae brasilis. Revista da Faculdade do Direito do Paraná. V. 46, p-27-50. Recuperado de : https://revistas.ufpr.br/direito/article/view/13495

Tardif M. (2006). Saberes docentes e formação profissional. 6. ed. Petrópolis: Vozes.

Veiga I.P.A. (2008). Organização didática da aula: um projeto colaborativo de ação imediata. In: Veiga I.P.A. (Org.). Aula: gênese, dimensões, princípios e práticas. Campinas: Papirus.

Veiga I.P.A., Castanho M.E.L.M. (Orgs.) (2000). Pedagogia Universitária: a aula em foco. Campinas: Papirus.

Villas Boas R.M.F. (2000). Avaliação no trabalho pedagógico universitário. In: Castanho S., Castanho M.E.L.M. (Orgs.). O que há de novo na educação superior - do projeto à prática transformadora. Campinas: Papirus.

Wolkmer A.C. (2001). Introdução ao pensamento jurídico crítico. São Paulo: Saraiva. 